\title{
Compressional waves in the Earth's neutral sheet
}

\author{
M. Volwerk ${ }^{1,3}$, W. Baumjohann ${ }^{1}$, K.-H. Glassmeier ${ }^{2}$, R. Nakamura ${ }^{1}$, T. L. Zhang ${ }^{1}$, A. Runov $^{1}$, Z. Vörös ${ }^{1}$, B. Klecker ${ }^{3}$, \\ R. A. Treumann ${ }^{3}$, Y. Bogdanova ${ }^{3}$, H.-U. Eichelberger ${ }^{1}$, A. Balogh ${ }^{4}$, and H. Rème ${ }^{5}$ \\ ${ }^{1}$ IWF, ÖAW, Graz, Austria \\ ${ }^{2}$ TU Braunschweig, Germany \\ ${ }^{3}$ MPE Garching, Germany \\ ${ }^{4}$ Imperial College, London, UK \\ ${ }^{5}$ CESR, Toulouse, France
}

Received: 27 August 2002 - Revised: 2 May 2003 - Accepted: 21 May 2003 - Published: 1 January 2004

\begin{abstract}
Compressional waves in the Earth's current sheet, driven by the high-speed plasma flows connected to substorms, are investigated using the Cluster magnetometer and plasma instrument. During the time that Cluster had its apogee in the magnetotail (July through October 2001), we have studied 5 events in detail. We find compressional waves in the $30-60 \mathrm{mHz}$ band, at a spectral power density that is dependent on when and where the event is observed. There is a difference of two orders of magnitude in power density between waves at substorm onset and waves during quiet times. Strong plasma flows are the driver of the wave power. The spacecraft location in the current sheet is also important for the spectral power density. Having four spacecraft available we can discern spatial from temporal variations. We have determined the propagation direction of the waves in the 30$60 \mathrm{mHz}$ band and found that in the Cluster rest frame they propagate in the same direction as the plasma flow at an angle $30^{\circ}<\Delta \phi<40^{\circ}$ with respect to the plasma flow direction in the spacecraft' rest frame.
\end{abstract}

Key words. Magnetospheric physics (magnetotail; MHD waves and instabilities; plasma sheet)

\section{Introduction}

Waves in the Earth's magnetotail have been a subject of theoretical and experimental investigations since the late 1960s (see, e.g. Hruška and Hrušková, 1970). The plasma sheet model proposed by Harris (1962) is mostly used to describe the magnetic field in the tail. Theoretically, the possible wave modes in the magnetotail are investigated by solving the MHD equations using the Harris model as an equilibrium around which the various fields are perturbed. Examples of this method can be found in Roberts (1981a, b), Lee et al. (1988), Smith et al. (1997), Tirry et al.

Correspondence to: $\mathrm{M}$. Volwerk

(Martin.Volwerk@assoc.oeaw.ac.at)
(1997), Büchner and Kuska (1999), Yoon and Lui (2001) and Fruit et al. (2002a, b).

In situ satellite observations have provided information about the behaviour of the magnetotail. Compressional waves seem to constitute an important part of the dynamics of the magnetotail and its lobes - see, e.g. Chen and Kivelson (1991) and Bauer et al. (1995a, b) and references therein. Also, the whole magnetotail can be flapping (Sergeev et al., 1998, 2003). The experimental investigations have not been limited to the Earth's magnetotail, but have also been extended to the magnetotails of the outer planets (Khurana et al., 1992).

The use of multi-spacecraft observations has proven to be very enlightening in obtaining both temporal and spatial resolution of the processes taking place in the Earth's magnetotail (see, e.g. Zhou et al., 1997). With the availability of the Cluster spacecraft we have four similar spacecraft that can be used to investigate, amongst others, the magnetotail.

Plasma flows, which form an important part in the analysis of our data, have been extensively studied. It has been pointed out by Nagai and Machida (1998) that the pre-midnight sector is the most active, which has been nicely confirmed by Raj et al. (2002), using Wind measurements of high-speed bulk flows. Other studies on the importance of burst flows in the inner central plasma sheet are presented by, for example, Baumjohann et al. (1990), Angelopoulos et al. (1992) using AMPTE/IRM data and Angelopoulos et al. (1994), making a statistical study of bursty bulk flows combining AMPTE/IRM and ISEE 2 data, and by Baumjohann et al. (2002) using Geotail data.

In this paper we will extend the investigation of Bauer et al. (1995a, b) by making case studies of five events, using the magnetic field (Balogh et al., 2001) and plasma measurements (Rème et al., 2001) from the four Cluster spacecraft. The Cluster spacecraft traversed the magnetotail in the period July through October 2001. The four spacecraft were set up to form an almost perfect tetrahedron while crossing the current sheet. The interspacing between the spacecraft was approximately $1800 \mathrm{~km}$. We will investigate the wave 


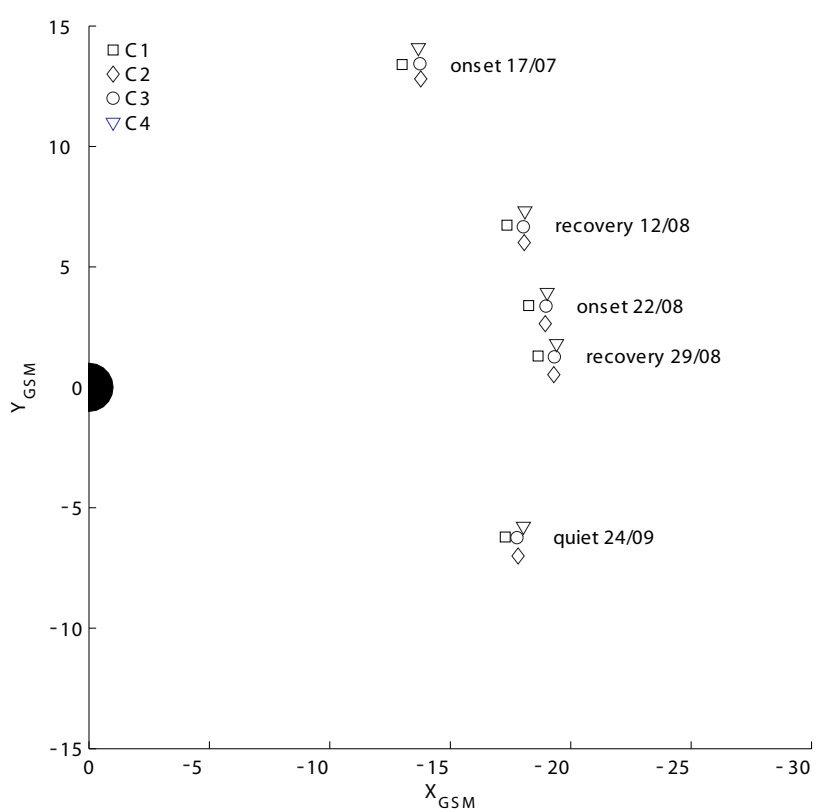

Fig. 1. Locations of all current sheet crossings for this paper in the GSM $x y$-plane. The location of 3 spacecraft are offset from the real location by $\pm 0.5 R_{E}$ in either the $x$ or $y$ direction, to show the relative location better. The offsets are in the following way: $\mathrm{C} 1$ $0.5 R_{E}$ earthward, C2 $0.5 R_{E}$ duskward and C4 $0.5 R_{E}$ dawnward. $\mathrm{C} 3$ is at its true location in the $x y$-plane, the southern-most of the four spacecraft.

power during neutral sheet crossings at three different magnetospheric activity levels: 1 . at substorm onset/during the expansion phase in Sect. 2; 2. during the late substorm (recovery) phase and re-intensification in Sect. 3; and 3. at quiet times in Sect. 4. The locations of all encounters in the GSM $x y$-plane can be seen in Fig. 1. In this figure we have offset 3 spacecraft from their true location by $\pm 0.5 R_{E}$ in the following way: $\mathrm{C} 10.5 R_{E}$ earthward, C2 $0.5 R_{E}$ duskward and $\mathrm{C} 40.5 R_{E}$ dawnward. $\mathrm{C} 3$ is at its true location in the $x y$-plane, the southern-most of the four spacecraft. This offset keeps the basic shape of the tetrahedron, but shows the relative locations of the spacecraft better.

\section{Substorm onset/expansion phase}

The first two events that we will investigate occur during a substorm expansion phase, as defined by a sudden increase in the $\mathrm{AE}$ index. They are the neutral sheet crossings on 17 July and 22 August 2001. The magnetometer data from the 4 spacecraft and the CODIF CIS $v_{\mathrm{x}}$ data for protons are shown in Figs. 2 and 3 in GSM coordinates. The region of interest for our wave investigation is marked by a gray box in the figures. Throughout this paper we will use the colour blue and a dash-dotted line for $\mathrm{C} 4$ and adhere to the other regular colours/line styles (C1 black/solid line, $\mathrm{C} 2$ red/dotted line, $\mathrm{C} 3$ green/dashed line) for the Cluster spacecraft.
We investigate the spectral power density of the compressional component of waves in the current sheet. The data are transformed to a mean field-aligned coordinate system which is calculated from low-pass filtered data (Butterworth filter which passes signals with periods $\tau \geq 5 \mathrm{~min}$ ). We combine the two transverse components in the mean-field-aligned system to a left- and a right-hand polarized component. The sampling rate of the data was 22 vectors per second, leading to a Nyquist frequency $f_{\mathrm{Ny}}=11 \mathrm{~Hz}$, and the power spectra are averaged over 7 spectral harmonics, and we have a spectral resolution of $\Delta f \approx 10^{-3} \mathrm{~Hz}$ (depending on the length of the interval). The power in the left- and right-hand polarized waves is an order of magnitude smaller than that in the compressional waves (see Fig. 4a and Bauer et al., 1995a, b) and therefore, we will concentrate on the compressional waves. This holds for all events discussed in this paper. Also, one finds that the main spectral power for all cases is in the Pi2 frequency range $(8-25 \mathrm{mHz})$. We will not discuss these waves in this paper, but concentrate on signatures at higher frequencies.

\subsection{The data}

17 July: The interval of interest is 17:23-17:34 UT. The AE index for this day shows an increase up to $500 \mathrm{nT}$, with the maximum reached at approximately 17:45 UT. The plasma data from Cluster show a fast earthward flow (CIS CODIF data) of $v_{\mathrm{x}} \geq 400 \mathrm{~km} / \mathrm{s}$ (bottom panel in Fig. 2) and little flow in the $y$ and $z$ directions (not shown in Fig. 2).

22 August: The interval of interest is 09:50-10:02 UT. The $\mathrm{AE}$ index for this day shows an increase up to $500 \mathrm{nT}$, starting at approximately 09:50 UT, while reaching a maximum at 10:15 UT. The plasma data from Cluster show that during the interval 09:50-09:54 UT, there is significant tailward flow, typically $v_{\mathrm{x}} \approx-300 \mathrm{~km} / \mathrm{s}$, with strong bursts up to $v_{\mathrm{x}} \approx-900 \mathrm{~km} / \mathrm{s}$ and during the interval 09:54-10:02 UT, a strong earthward flow is established with $v_{\mathrm{x}} \approx 500 \mathrm{~km} / \mathrm{s}$. The $v_{\mathrm{y}}$ component shows some flow $v_{\mathrm{y}} \approx 200 \mathrm{~km} / \mathrm{s}$ during the first interval and returns to small variations around $0 \mathrm{~km} / \mathrm{s}$ in the second interval. There is no flow in the $z$ component. ( $v_{\mathrm{y}}$ and $v_{\mathrm{z}}$ are not shown in Fig. 3.)

\subsection{Wave analysis}

\subsubsection{July 2001}

The interval of interest on 17 July shows a well developed harmonic spectrum, Fig. 4b. All four spacecraft show a peak around $40 \mathrm{mHz}$. A strong variation in spectral power density appears in the different spacecraft. C4 shows the greatest power density, followed by $\mathrm{C} 3, \mathrm{C} 2$ and finally, $\mathrm{C} 1$, at approximately 0.3 times the power density of $\mathrm{C} 4$.

Closer inspection of the power spectra shows that $\mathrm{C} 1$ and $\mathrm{C} 2$ (Fig. 4c) show a harmonic spectrum: the main power is in the Pi2 band at $15 \mathrm{mHz}$, possibly there is a peak at $25 \mathrm{mHz}$, and then more harmonics at frequency steps $\delta f \approx 17 \mathrm{mHz}$. However, C3 and C4 (Fig. 4d) show a different kind of 


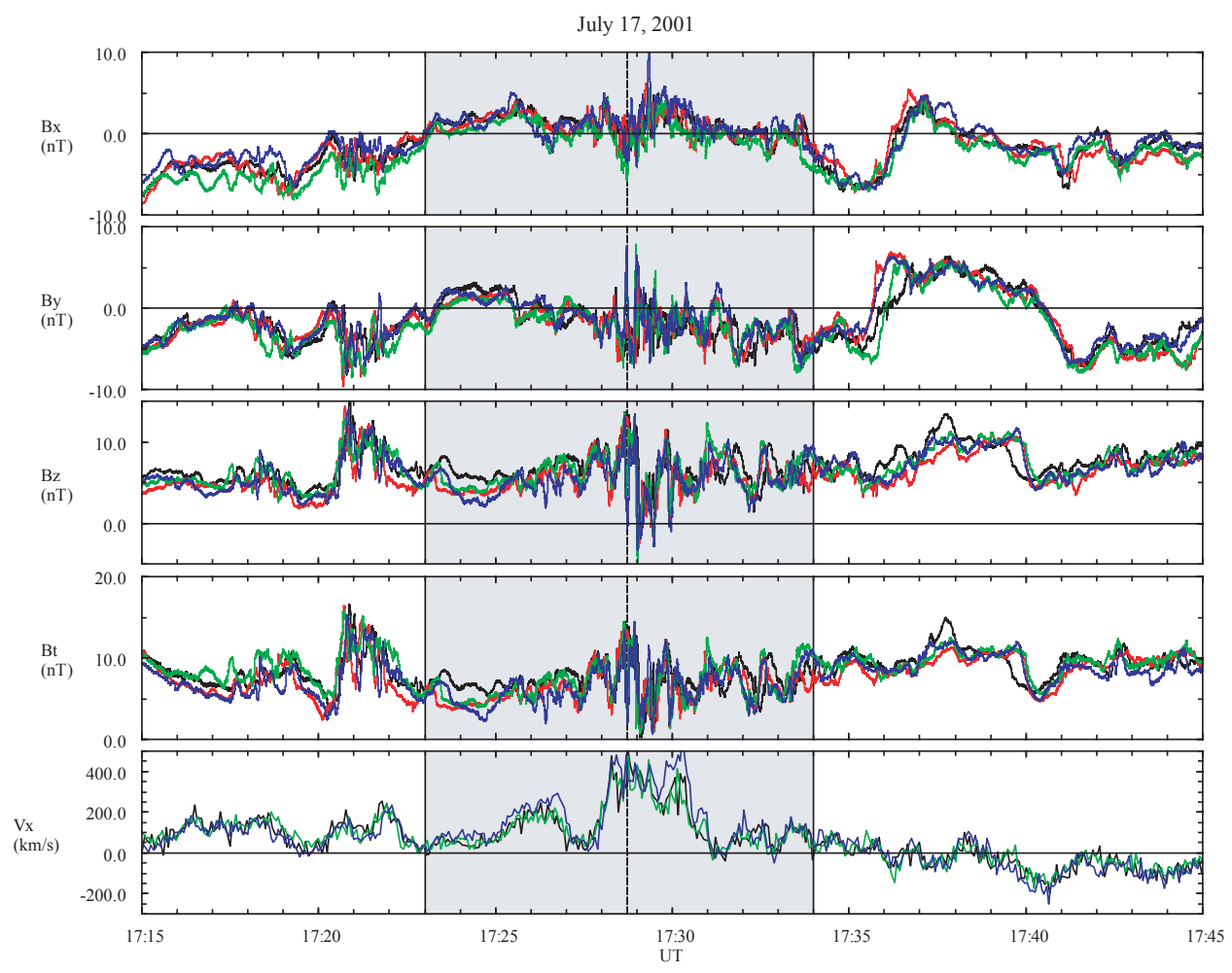

Fig. 2. The Cluster magnetometer and plasma instrument data for 17 July 2001. The five panels show the three components and the magnitude of the magnetic field in the GSM coordinate system, and the $v_{\mathrm{x}}$ component of the plasma flow from the CIS CODIF instrument for $\mathrm{C} 1 / 3 / 4$. The gray box shows the interval of interest for our investigation, in which the spacecraft cross the neutral sheet and strong magnetic fluctuations are visible.

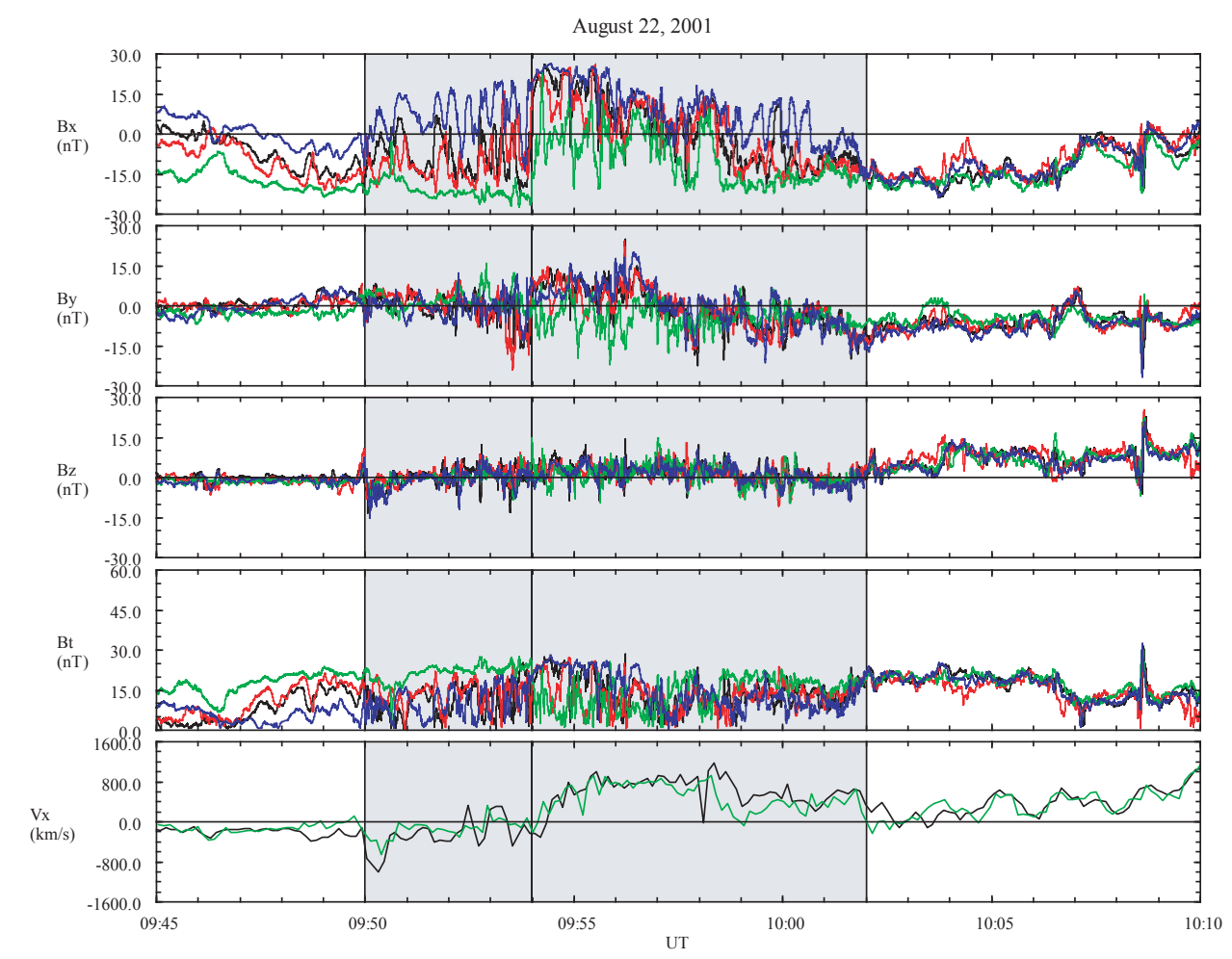

Fig. 3. The Cluster magnetometer and plasma instrument data for 22 August 2001. 

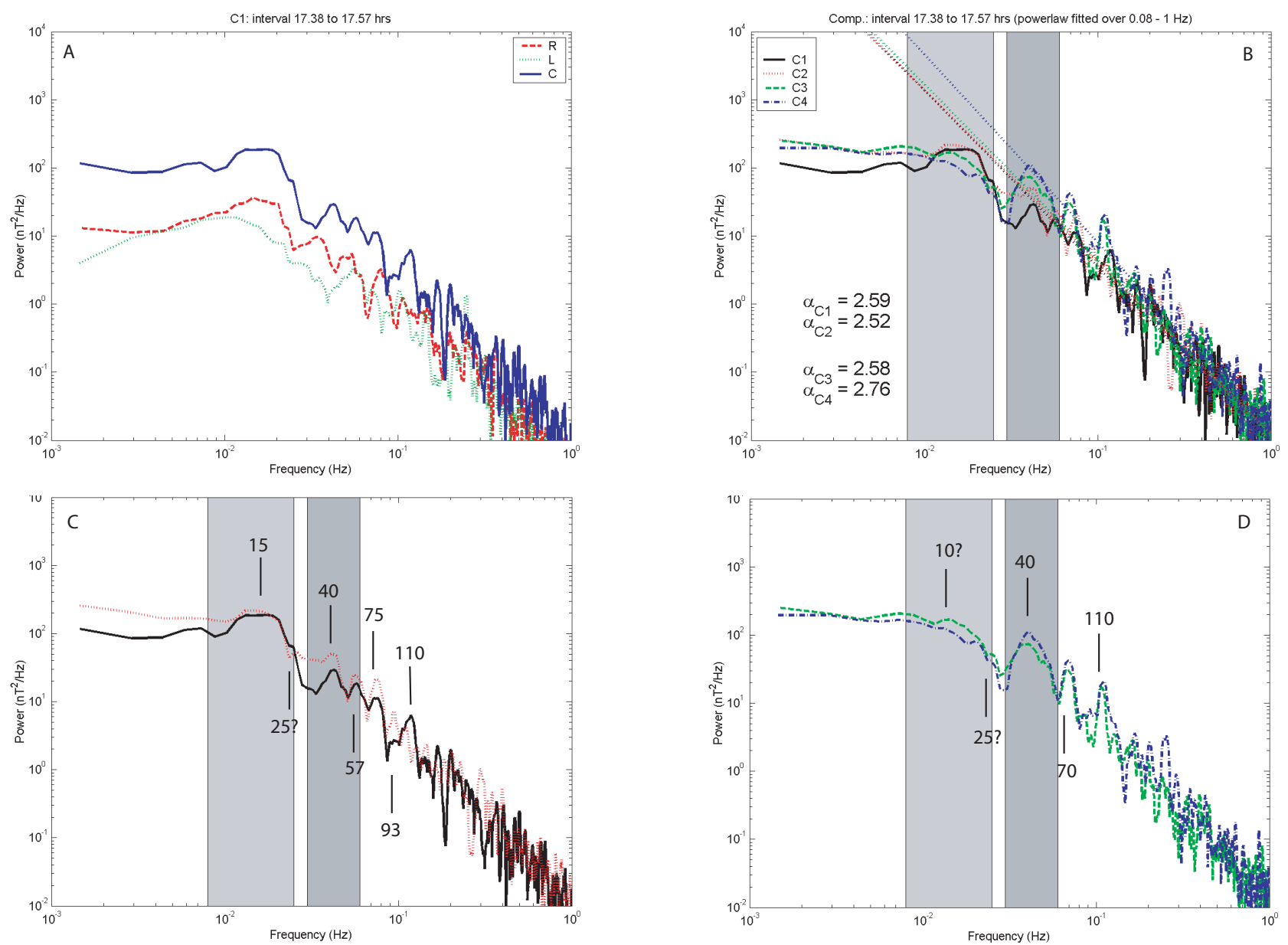

Fig. 4. Power spectra for the 17 July data. Panel (a): The spectral power density of the right-hand (R) and left-hand (L) polarized waves and the compressional (C) waves for $\mathrm{C} 1$. The compressional wave power is dominant over most of the frequency range. Panel (b): The spectral power density in the compressional waves for all spacecraft and the power law fit $\left(P(f)=P_{0} \exp \{-\alpha f\}\right)$ to the spectrum for the interval 80-1000 mHz. Panel (c): The power spectra for C1 and C2 with indicated spectral peak frequencies. Panel (d): The power spectra for C3 and $\mathrm{C} 4$ with indicated spectral peak frequencies.

behavior, with a harmonic spectrum starting at possibly $25 \mathrm{mHz}$ (with some minimal structure similar as in C1/2) and definitely at $40 \mathrm{mHz}$, with frequency steps $\delta f \approx 30 \mathrm{mHz}$. We will discuss the origin of these harmonic waves in Sect. ??.

The availability of four spacecraft measurements of the magnetic field gives the opportunity to determine the propagation direction and the velocity of these compressional waves. We have band-pass filtered the data $(30 \leq f \leq 60 \mathrm{mHz}$, using a Butterworth filter) and then determined the crosscorrelation between $\mathrm{C} 1$ and the three other spacecraft, see Fig. 5 top panel. The lag time between the spacecraft is determined from the maximum in the cross-correlation. The lag time between the spacecraft and the location of the spacecraft are least-square fitted to obtain the three-dimensional velocity vector, $\boldsymbol{v} \approx(287,53,-18) \mathrm{km} / \mathrm{s}$, with respect to the tetrahedron. (A more elaborate method for determining the wave propagation direction is described by Glassmeier et al. (2001). Unfortunately, this method needs much longer time intervals than are available in our case.) These compres- sional waves thus move in the same direction as the plasma flow, which was earthward at $v_{\mathrm{x}} \geq 500 \mathrm{~km} / \mathrm{s}$ (see above), but at different speed. The waves also propagate under an angle $\Delta \phi \approx 32^{\circ}$ with respect to the plasma flow.

\subsubsection{August 2001}

For 22 August we split the interval into two parts: A. 09:5009:54 UT, in which the plasma flow is mainly tailward; and B. 09:54-10:02 UT, in which the plasma flow is strongly earthward. Again, the plasma flow is similar for all three spacecraft for which data is available, as can be seen in the bottom panel of Fig. 3 .

The power spectrum for interval A is shown in Fig. 6a, in which it is clear that enhanced power exists in the $30-60 \mathrm{mHz}$ band. It is well developed in $\mathrm{C} 4$, whereas $\mathrm{C} 1 / 2 / 3$ show a more plateau-like structure which is the low-frequency end of a broad structured spectral maximum extending up to $\sim 0.2 \mathrm{~Hz}$. From the data (Fig. 3) it is clear that the spacecraft are in different regions of the current sheet. C3 is still 
in the lobe, and sees little wave power, $\mathrm{C} 1 / 2$ are entering the current sheet and see oscillations in $B_{\mathrm{x}}$, and $\mathrm{C} 4$ has crossed the neutral sheet and sees well developed oscillations in $B_{\mathrm{X}}$ at $\sim 25 \mathrm{~s}$. The higher frequency maximum shows peaks between $70-100 \mathrm{mHz}$ for $\mathrm{C} 1 / 2 / 4$, and a peak at approximately $120 \mathrm{mHz}$ for $\mathrm{C} 1 / 4$.

We band-pass filter the data of interval A to determine the propagation direction of the waves in the $30-60 \mathrm{mHz}$ band. The cross-correlation between the spacecraft is not as good as in the 17 July case, as can be seen in Fig. 5, bottom panel. Especially between $\mathrm{C} 1$ anc $\mathrm{C} 3$ the cross-correlation is poor, which is not surprising, since from the magnetic field data there is little wave power present. The different peaks in the cross-correlation are separated by approximately $25 \mathrm{sec}$, which is one period of the central frequency of our band-pass filters. One cannot just take the maximum cross-correlation for this event, which the data clearly shows when checked. For the C3 trace we have to take the lower extremum at $\sim-6 \mathrm{~s}$, for a consistent propagation direction. This also means that we have to be skeptical about the resulting velocity vector. We find that $\boldsymbol{v} \approx(-140,42,5) \mathrm{km} / \mathrm{s}$. The propagation angle with respect to the plasma flow is $\Delta \phi \approx 30^{\circ}$.

For interval $\mathrm{B}$ the power spectrum is shown in Fig. $6 \mathrm{~b}$. Clearly the peaks in the $30-60 \mathrm{mHz}$ band are dominant now in all spacecraft, albeit not centered on one frequency, but shifted per spacecraft. It is noteworthy that this peak is followed again by a broad spectral excess in the $80-200 \mathrm{mHz}$ band. The magnetic data show that for this interval all spacecraft exhibit a more similar behavior, even though there are slight differences. C3 remains near the neutral sheet, whereas $\mathrm{C} 1 / 2 / 4$ move into the lobe and then return to the neutral sheet and cross it again, back to the southern lobe, with $\mathrm{C} 4$ remaining near the neutral sheet, like in interval $\mathrm{A}$, and showing again clear 25-sec oscillations in $B_{\mathrm{X}}$. At higher frequencies there are no significant peaks in the spectrum except for the spectral excess mentioned above.

Band-pass filtering the data and calculating the cross-correlation shows that there is reasonable correlation for $\mathrm{C} 2$ and $\mathrm{C} 4$ and a bad correlation for $\mathrm{C} 3$. The resulting velocity is $\boldsymbol{v} \approx(223,38,202) \mathrm{km} / \mathrm{s}$. The propagation angle with respect to the plasma flow is $\Delta \phi \approx 35^{\circ}$.

\section{Late substorm phase and substorm re-intensification}

Now we will look at data during the late substorm phase and re-intensification. In the first event that we have chosen, 12 August 2001, there is a lot of dynamics going on in the current sheet. The data show a thinning current sheet (Nakamura et al., 2002a), sending the spacecraft to either side of it and a high wave power in the magnetic field. The second event on 29 August 2001 has the spacecraft move into the current sheet, but they do not cross $B_{\mathrm{x}}=0$.
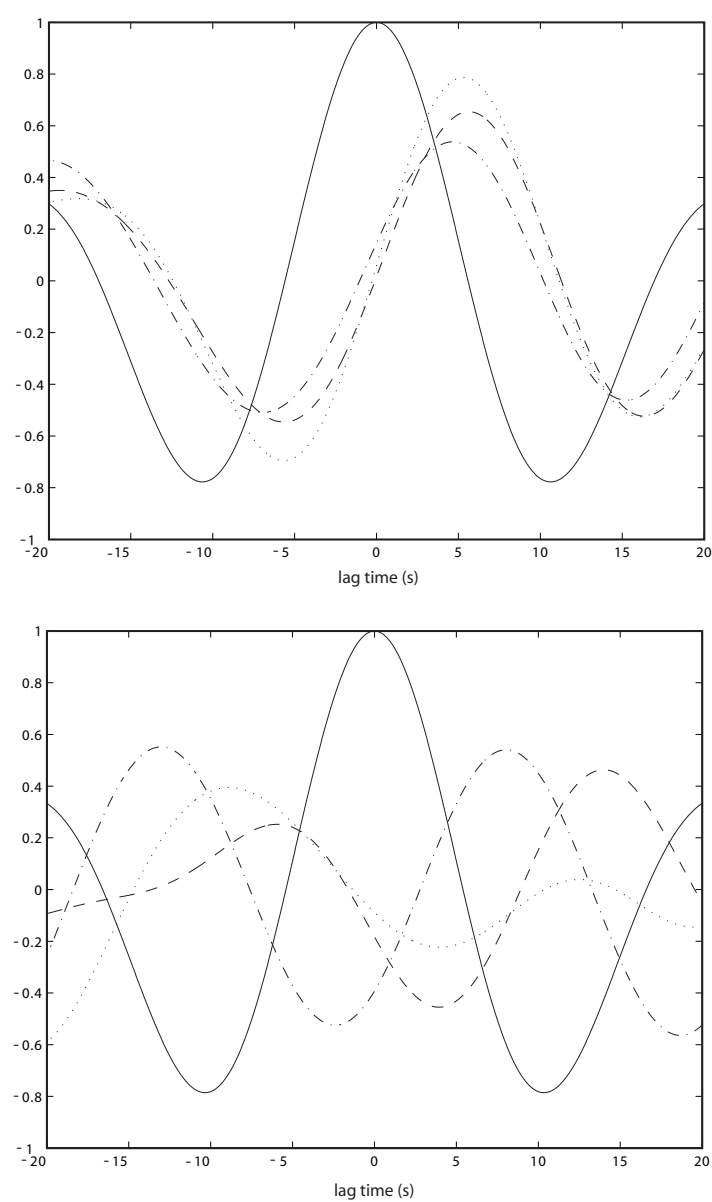

Fig. 5. Top: The cross-correlation of the band-pass filtered $(30 \leq f \leq 60 \mathrm{mHz}$ ) data of 17 July 2001 . C1/C1 (solid), C1/C2 (dotted), $\mathrm{C} 1 / \mathrm{C} 3$ (dashed) and $\mathrm{C} 1 / \mathrm{C} 4$ (dash-dotted) as a function of the lag time in seconds. There is good correlation for C2 and C3 (0.8 and 0.65 , respectively) and reasonable correlation for $\mathrm{C} 4(0.55)$. The lag times for these maximal correlations (5.3, 5.6 and $4.6 \mathrm{sec}$, respectively) are used to calculate the propagation direction and velocity of the waves using the spacecraft locations. Bottom: The cross-correlation for the data of 22 August 2001, interval A as a example of partially poor correlation between spacecraft.

\subsection{The data}

The first event is on 12 August 2001. The interval of interest is 18:38-18:46 UT, during which there are fast earthward flows $\left(v_{\mathrm{x}} \geq 700 \mathrm{~km} / \mathrm{s}\right)$, and there is also a pronounced thinning of the current sheet up to a half thickness $\lambda \leq 500 \mathrm{~km}$ (Nakamura et al., 2002a). The AE index shows that this event takes place in the recovery phase of a substorm, with AE approximately $500 \mathrm{nT}$ after a maximum of $700 \mathrm{nT}$ approximately 15 min earlier. However, the AE index is not a good substorm indicator for this event. The auroral images show that at the beginning of this interval, there is an auroral brightening, thus we are dealing with a re-intensification of the substorm. The magnetic field data and CIS CODIF $v_{\mathrm{x}}$ data for protons in GSM coordinates are shown in Fig. 7.

The second event is on 29 August 2001, during the time 

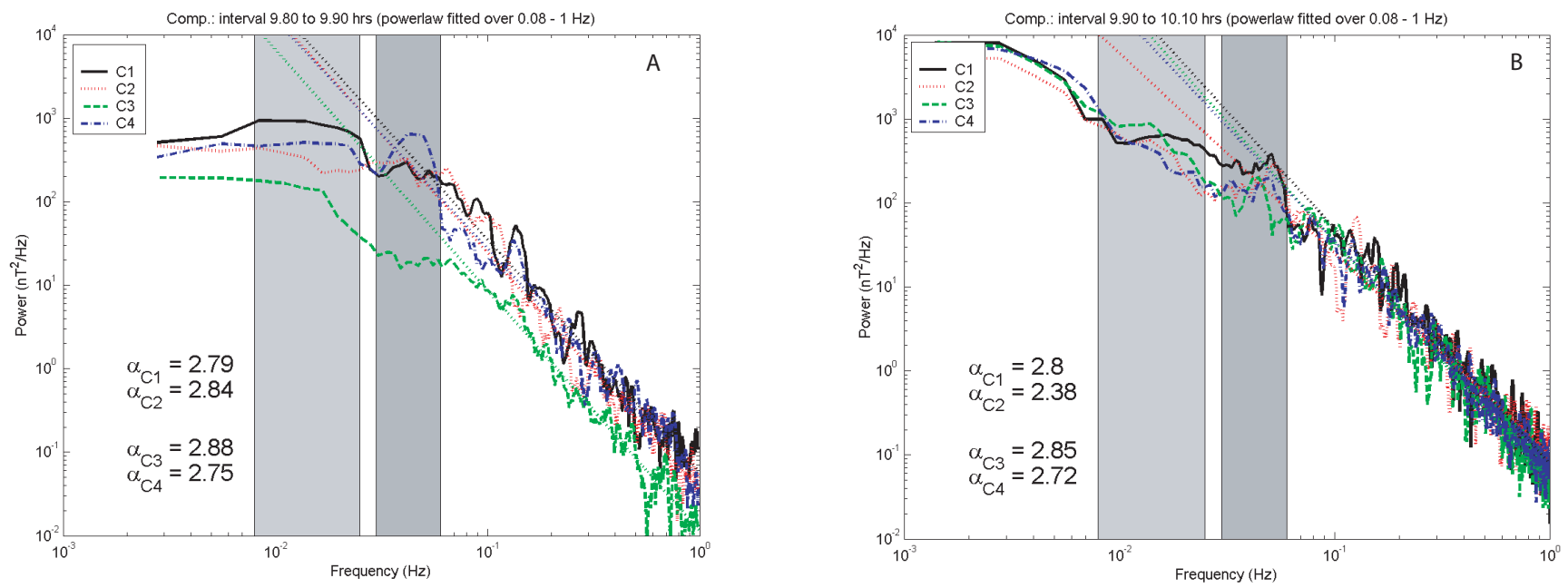

Fig. 6. Power spectra for the 22 August data. Panel (a): The power spectra for all spacecraft for the interval 09:50-09:54 UT. Panel (b): The power spectra for all spacecraft for the interval 09:54-10:02 UT.

interval 1:24-11:27 UT. There is little fluctuating flow in all components and just before the interval, the plasma $\beta$ increased from 0.1 to 1 . The AE index shows that this interval is during a substorm late recovery phase, with $\mathrm{AE}$ flattening out at approximately $200 \mathrm{nT}$ after a maximum of $600 \mathrm{nT}$. In the FGM data a clear signature in $B_{\mathrm{x}}$ at this time, which changes from $B_{\mathrm{X}} \approx-8 \mathrm{nT}$ to $B_{\mathrm{x}} \geq 0 \mathrm{nT}$, is associated with a decrease in the total magnetic field strength $B_{\mathrm{t}}$ and a strong earthward flow $v_{\mathrm{x}} \approx 400 \mathrm{~km} / \mathrm{s}$. The magnetic field data and CIS CODIF $v_{\mathrm{x}}$ data for protons in GSM coordinates are shown in Fig. 8. There are some significant flows in $y$ and $z$ (not shown in Fig. 8), on the order of half the flow in $x$. The Kaktovik magnetometer of the GIMA array shows that there is a strong negative bay in the $\mathrm{H}$ component (positive bay in the $\mathrm{Z}$ component).

\subsection{Wave analysis}

\subsubsection{August 2001}

We show the power spectrum for the 12 August interval in Fig. 9a. C1 and C3 exhibit peaks in the $30-60 \mathrm{mHz}$ band, $\mathrm{C} 2$ shows a slight peak near $50 \mathrm{mHz}$, and $\mathrm{C} 4$ shows a plateau with no specific peaks. We have split the interval into two halves, and calculated the power spectrum for both, shown in Figs. 9b and 9c. This is done basically because first, $\mathrm{C} 3$ is in the same tail region as the other three spacecraft, but in the second half it is at the opposite side of the neutral sheet. The resulting spectra show slight differences between the two halves, basically in the behaviour of $\mathrm{C} 3$, which has a plateau first in the spectrum and then a peak. The spectral power density in the peaks is between 10 and $100 \mathrm{nT}^{2} / \mathrm{Hz}$. This is an order of magnitude smaller than the previous two examples, indicating that the compressional waves in the current sheet are damped, or that the spacecraft have moved into a location of the current sheet where these waves are suppressed (this topic will be further discussed in Sect. 5.1).
For both halves we band-pass filter the data to find the direction and velocity of propagation of the waves. For the first half the correlation with $\mathrm{C} 4$ is good, $\sim 0.8$, however, those for $\mathrm{C} 2$ and $\mathrm{C} 3$ are between 0.5 and 0.6. So we must again be careful with interpreting our result. The waves propagate with velocity $\boldsymbol{v} \approx(140,-78,88) \mathrm{km} / \mathrm{s}$ earthward, while the plasma flow is earthward at $v_{\mathrm{x}} \geq 700 \mathrm{~km} / \mathrm{s}$. The propagation angle with respect to the plasma flow is $\Delta \phi \approx 39^{\circ}$.

For the second half we find similar correlations between the spacecraft, with different lag times. The waves propagate with $\boldsymbol{v} \approx(67,-20,11) \mathrm{km} / \mathrm{s}$ earthward, while the plasma flow is earthward at $v_{\mathrm{x}} \geq 700 \mathrm{~km} / \mathrm{s}$. The discrepancy between the two determined velocities is likely to be an artifact from the weak correlation of $\mathrm{C} 2$ with the other spacecraft. The correlation between $\mathrm{C} 1 / 3 / 4$ is reasonably good, even though $\mathrm{C} 3$ is mainly at the opposite side of the neutral sheet as $\mathrm{C} 1 / 4$.

\subsubsection{August 2001}

The power spectrum for the second event, 29 August, is shown in Fig. 10. There are no significant peaks in the $30-60 \mathrm{mHz}$ band, slight plateaus in C $3 / 4$ and just a fall-off in $\mathrm{C} 1 / 2$. The main spectral features are at higher frequencies, between 80 and $150 \mathrm{mHz}$. Band-pass filtering the data over this higher frequency range shows reasonable correlation between the spacecraft, with values between 0.7 and 0.8 . The resulting direction and velocity of the waves is $\boldsymbol{v} \approx(260,-82,129) \mathrm{km} / \mathrm{s}$. The propagation angle with respect to the plasma flow is $\Delta \phi \approx 35^{\circ}$.

\section{Quiet time}

The last event that we will investigate is during quiet times, on 24 September 2001. The AE index for this day shows very little activity, constant at less that $200 \mathrm{nT}$ over a period of more than $6 \mathrm{~h}$. There are no significant flows in the current sheet. 


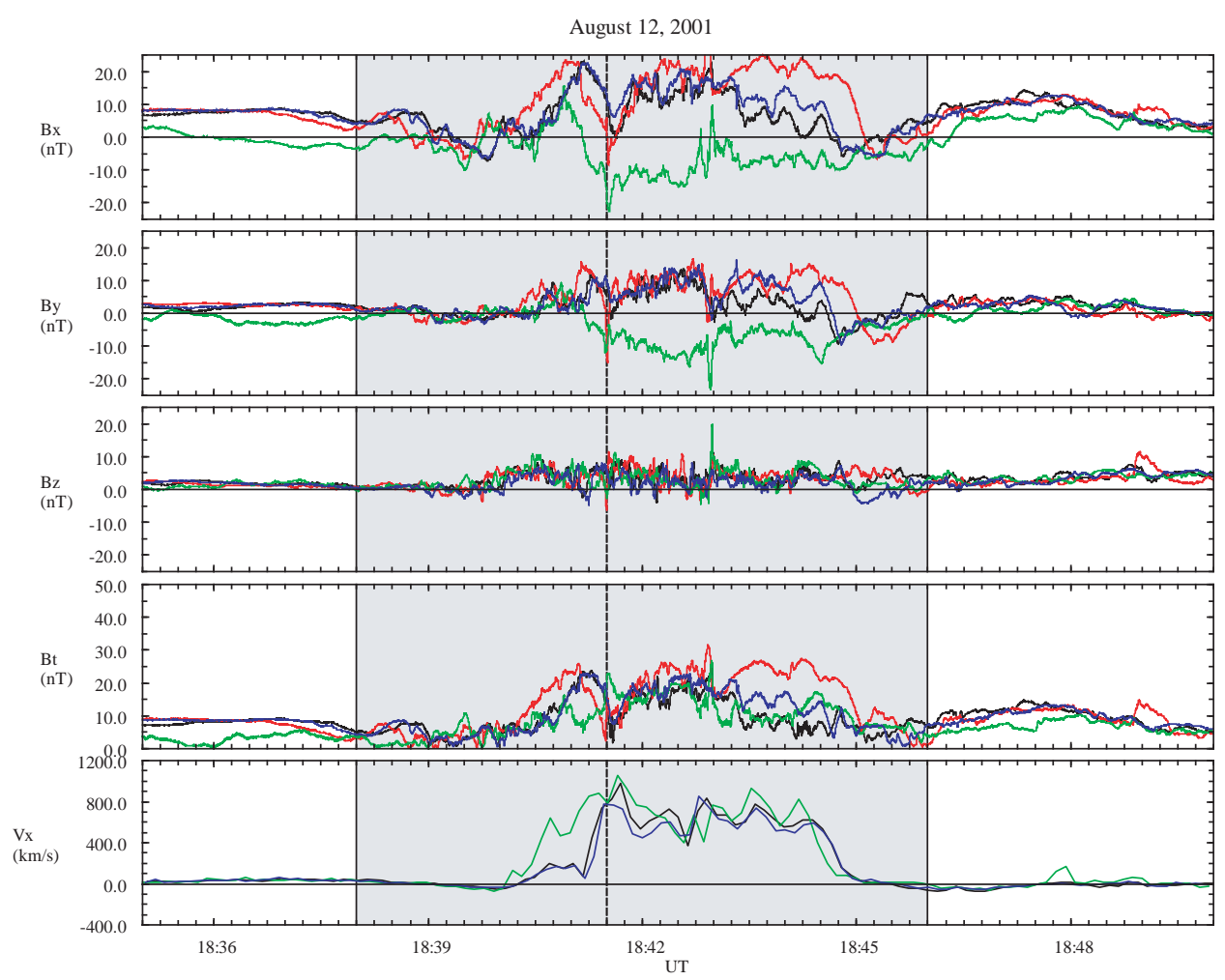

Fig. 7. The Cluster magnetometer and plasma instrument data for 12 August 2001.

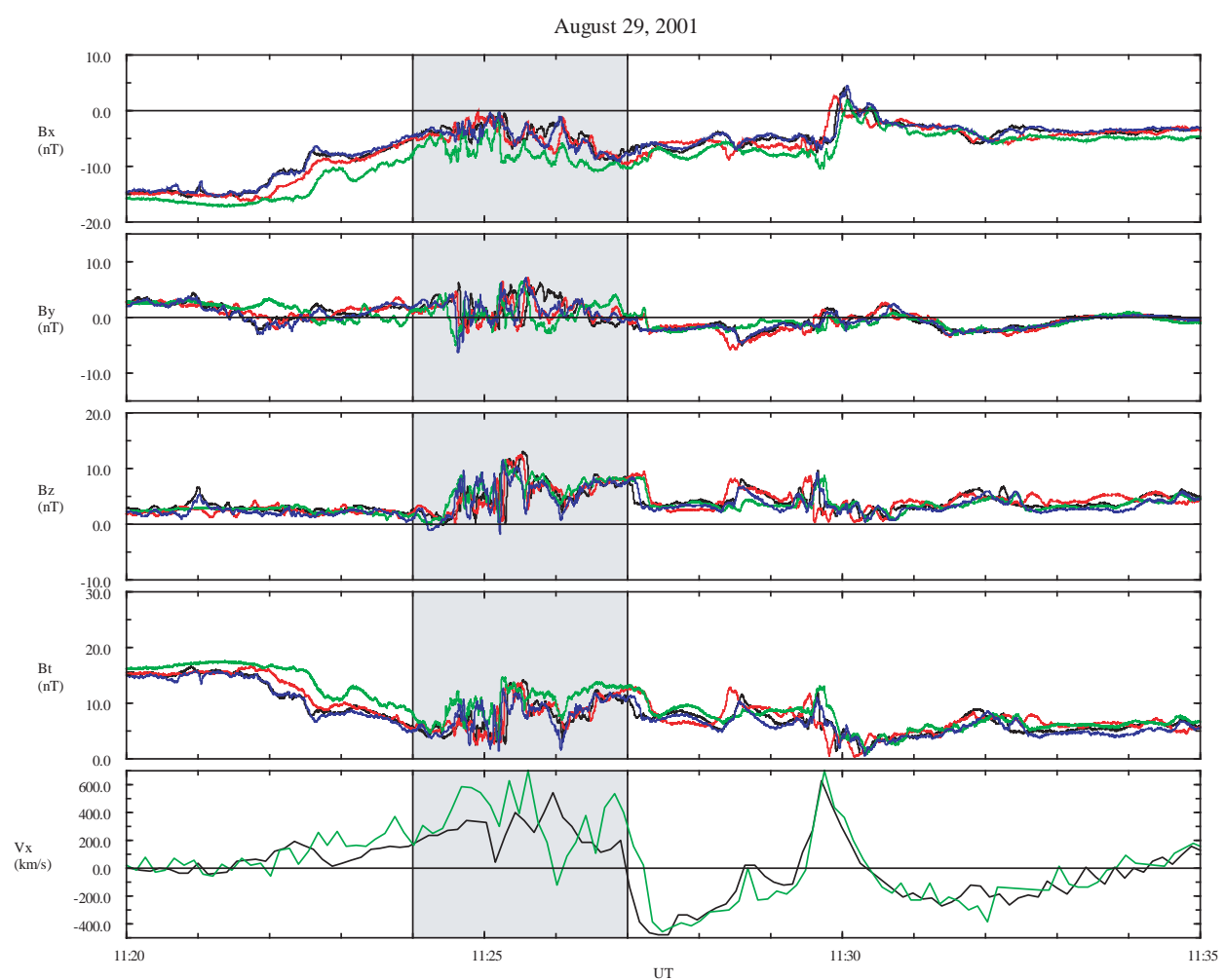

Fig. 8. The Cluster magnetometer and plasma instrument data for 29 August 2001. 

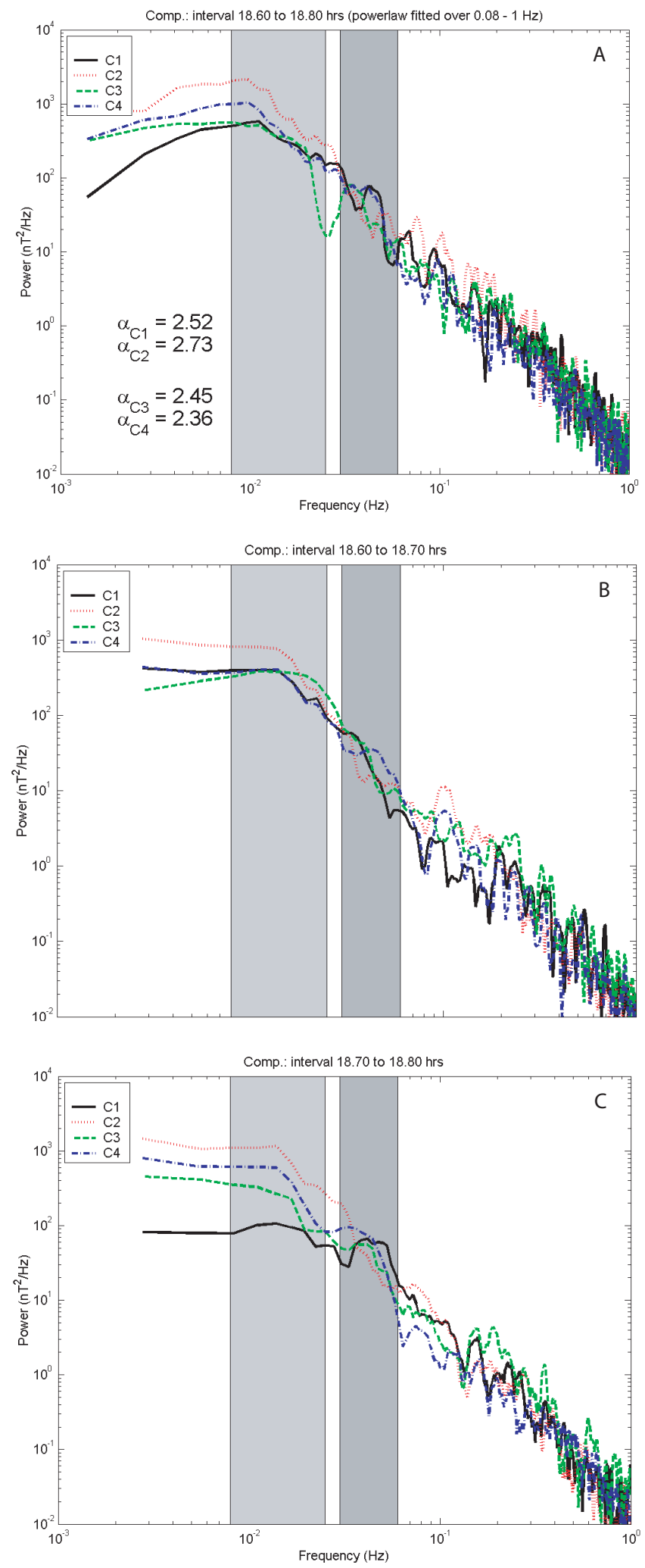

Fig. 9. The power spectra for the 12 August data. Panel (a): The power spectra for all spacecraft for the total interval 18:3818:46 UT. Panel (b): The power spectra for all spacecraft during the first half of the interval, with $\mathrm{C} 3$ in the same region as $\mathrm{C} 1 / 2 / 4$. Panel (c): The power spectra for all spacecraft during the second half of the interval, with $\mathrm{C} 3$ at the opposite side of the neutral sheet with respect to $\mathrm{C} 1 / 2 / 4$. For clarity the fitted power laws have not been plotted in the panels.

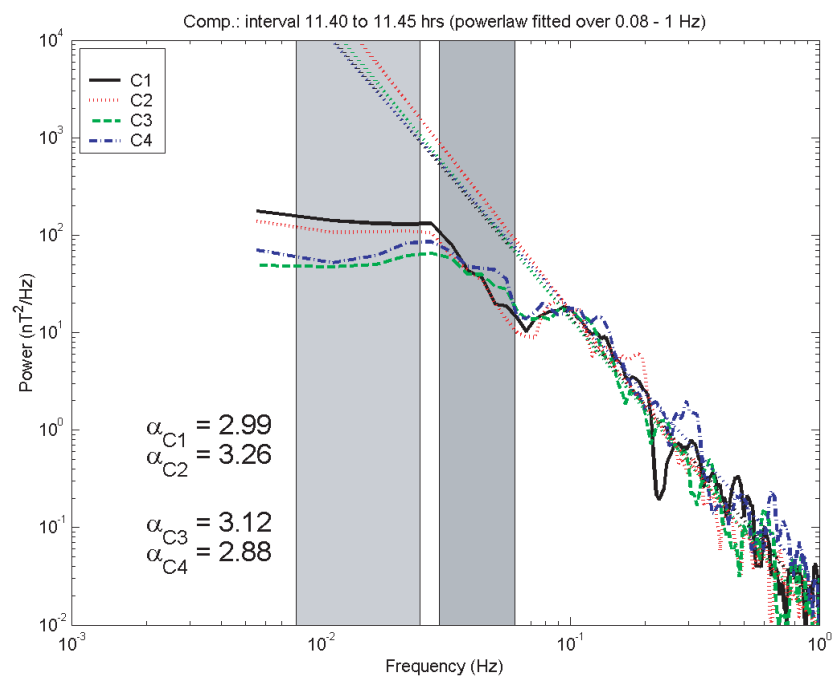

Fig. 10. The power spectra for the 29 August data.

\subsection{The data}

There are two interesting intervals for this event. For the first interval, 09:39-09:48 UT, all spacecraft are in the current sheet with little wave power in the magnetometer data, shown in Fig. 11, together with CODIF CIS $v_{\mathrm{x}}$ data for protons. A clear dipolarization takes place during this interval at 09:40 UT, where $B_{\mathrm{Z}}$ increases from 5 to $15 \mathrm{nT}$. After the dipolarization has occurred the field lines stretch again and $\mathrm{C} 1 / 3 / 4$ show the same decrease in $B_{\mathrm{z}}$, whereas $\mathrm{C} 2$ shows a sudden dipolarization again at 09:43:50 UT.

In the second interval, 09:51-09:58 UT, there are strong $B_{\mathrm{X}}$ oscillations seen by the spacecraft. It is interesting that $\mathrm{C} 1 / 3 / 4$ basically show the same magnetic field oscillations, whereas $\mathrm{C} 2$ is clearly offset in time by approximately $30 \mathrm{sec}$.

From both intervals we find that $\mathrm{C} 2$ is in a slightly different region as $\mathrm{C} 1 / 3 / 4$. Indeed, looking at the locations of the spacecraft we find that $\mathrm{C} 1 / 3 / 4$ are at approximately the same $y_{\mathrm{GSM}}$, but C2 is significantly further dawnward.

\subsection{Wave analysis}

We show the power spectra for both intervals in Fig. 12. The first interval shows slight peaks that are still significant in $\mathrm{C} 1 / 3 / 4$ and a broad plateau in $\mathrm{C} 2$. The peaks do not line up well enough to validate the propagation direction determination. The spectral power in the peaks varies between 1 and $10 \mathrm{nT}^{2} / \mathrm{Hz}$. This decrease of another order of magnitude in spectral power shows that the waves in the current sheet are damped after substorm onset. The second interval does not show significant peaks in the power spectra.

\section{Discussion}

We have investigated several current sheet crossings by the Cluster spacecraft under varying magnetospheric conditions: 


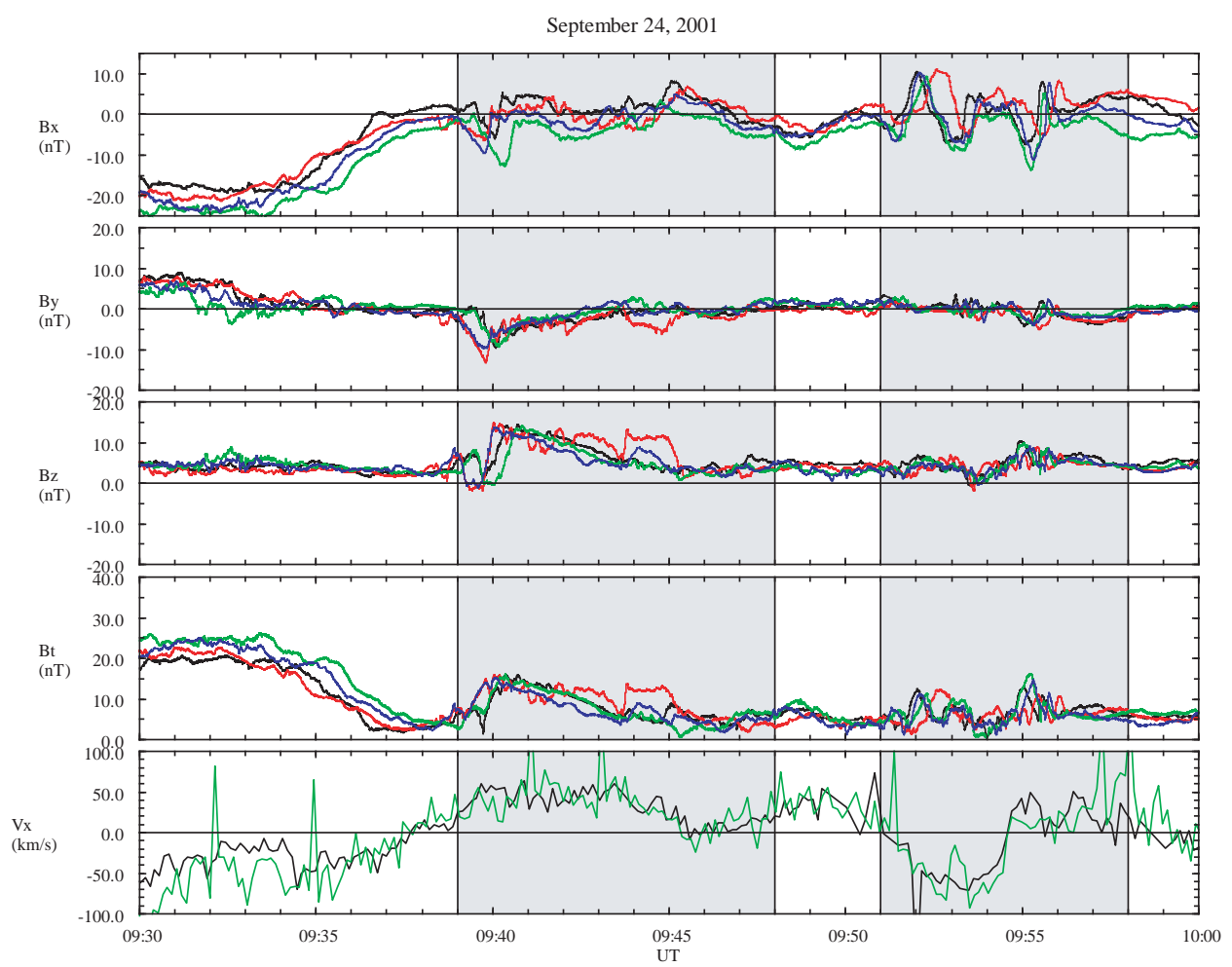

Fig. 11. The Cluster magnetometer and plasma instrument data for 24 September 2001.

1. at strong substorm onset/during the expansion phase; 2 . during late substorm phase and re-intensification; 3 . at quiet times. The main observations were:

- Compressional waves dominate over left- and righthand polarized waves in the current sheet;

- Compressional waves in the $30-60 \mathrm{mHz}$ band exist in the current sheet, with spectral power density dependent on the level of magnetospheric activity, with the strongest power at the substorm expansion phase and the weakest power during quiet times;

- In the spacecraft' reference frame the compressional waves move in the same direction as the plasma flows measured by Cluster, however, with smaller velocities;

- The propagation angle of the waves with respect to the flow direction is $30^{\circ} \leq \Delta \phi \leq 40^{\circ}$.

Our main interest extended out to waves in the $30-60 \mathrm{mHz}$ band, which seemed to be present in most of the spectra. Indeed, spectral peaks in the frequency range $0.001-0.16 \mathrm{~Hz}$ were observed by Sigsbee et al. (2001) in the Geotail data, when the spacecraft was moving through the current sheet. They, however, did not study these waves in detail.

Looking at the various spectra in this paper one can notice that there seems to be a strong dependence on the power spectral density of these peaks on the time of observation with respect to magnetospheric activity. At the substorm onset/expansion phase the maximum power is $10^{2} \leq P_{30-60}$ $\leq 10^{3} \mathrm{nT}^{2} / \mathrm{Hz}$, later we find $10 \leq P_{30-60} \leq 10^{2} \mathrm{nT}^{2} / \mathrm{Hz}$ and during quiet times $1 \leq P_{30-60} \leq 10 \mathrm{nT}^{2} / \mathrm{Hz}$. For each magnetospheric condition that we identified we find that the power spectral density differs by an order of magnitude. This could indicate that processes related to substorms, such as flow bursts, are the driving power behind these waves, which then dissipate over these events. However, our data sets are sufficiently different, in order to obtain a more detailed view of the dependencies of the wave power.

\subsection{Overview 30-60 $\mathrm{mHz}$ waves dependencies}

In the previous sections we have investigated the $30-60 \mathrm{mHz}$ waves per event. These five events occur in a broad range of magnetic activity, spacecraft location (in LT and with respect to the neutral sheet) and flow activity. This gives us the possibility to come to a general view of the criteria necessary for the occurrence of these waves.

The first event on 17 July the magnetic field measured by the spacecraft (see Fig. 2) does not show significant differences. All the spacecraft are clustered around the neutral sheet, $B_{\mathrm{x}}=0$. This indicates that the current sheet is thick with respect to the north-south separation distances of the spacecraft. In this case the current sheet half thickness $\lambda>1600 \mathrm{~km} \approx 0.25 R_{\mathrm{E}}$. The strongest wave power can be seen during the strong flow burst, $v_{\mathrm{x}}>400 \mathrm{~km} / \mathrm{s}$. This case, however, does not show whether both the location near the neutral sheet and the fast flows are determining factors. 

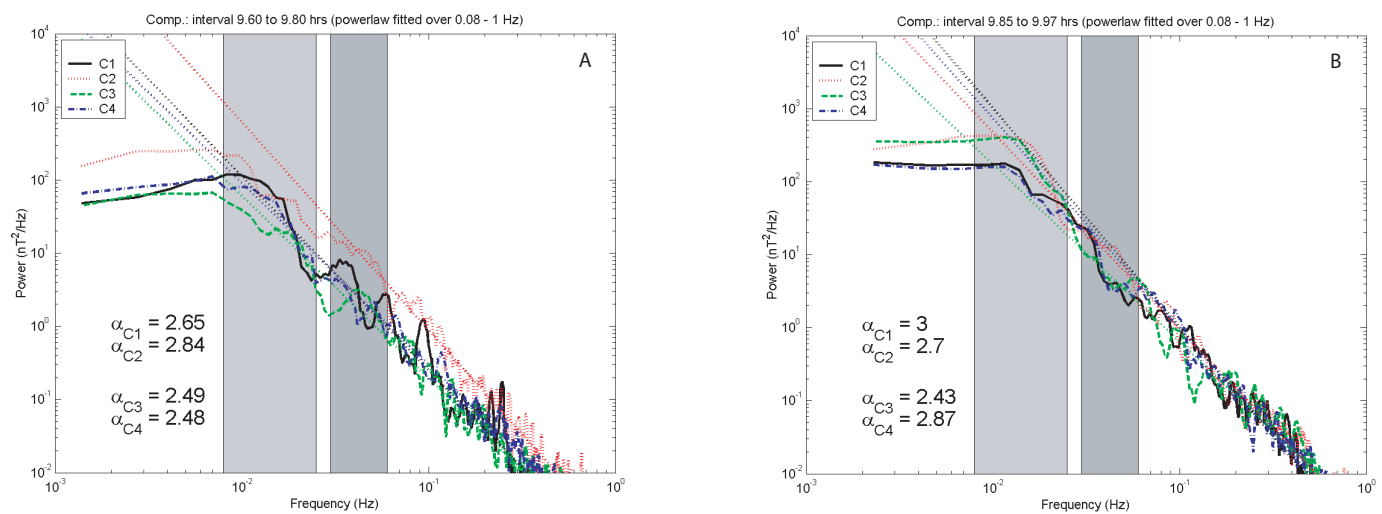

Fig. 12. The power spectra for the 24 September data. Panel (a): The power spectra for all spacecraft for interval 09:39-09:48 UT. Panel (b): The power spectra for all spacecraft for interval 09:51-09:58 UT.

The 22 August event gives more information with respect to this question. While the spacecraft were in the current sheet, the half thickness of the sheet decreased significantly from $\sim 2 R_{\mathrm{E}}$ to $\sim 0.2 R_{E}$ and back again (Volwerk et al., 2003). Using a Harris sheet model, given in Eq. (1), one can estimate the parameters of the current sheet model with three spacecraft, leaving the fourth spacecraft to check the result (cf. Nakamura et al. (2002a)). In our case we first fit the data from $\mathrm{C} 2 / 3 / 4$ and check with $\mathrm{C} 1$, and successively we then fit the data from $\mathrm{C} 1 / 3 / 4$ and check with $\mathrm{C} 2$

$B_{\mathrm{X}}(z)=B_{0} \tanh \left(\frac{z-z_{0}}{\lambda}\right)$

Here, $B_{0}$ is the magnetic field in the lobes, $z_{0}$ is the $z$-offset of the neutral sheet $\left(B_{\mathrm{x}}\left(z_{0}\right)=0\right)$ in GSM coordinates, and $\lambda$ is the half thickness of the current sheet. We have determined these parameters at various points along the interval for oneminute averaged data. Figure 13 shows the results for the interval 09:50-09:59 UT. For a good fit one expects:

$\frac{\Delta B_{\mathrm{X}}}{B_{\mathrm{x}}}=\left|\frac{B_{\mathrm{x}, \mathrm{C} 1 / 2}-B_{\mathrm{x}, \mathrm{fit}}}{B_{\mathrm{x}, \mathrm{C} 1 / 2}}\right|<1$,

which, for most points in Fig. 13, is the case. Once again, there is a strong flow in the current sheet (see Fig. 3), but now the current sheet has a large-scale flapping motion across the spacecraft, sending them from one side to the other. One can observe some clear effects from this flapping motion. Starting at 09:50 UT, there is a strong tailward flow burst, which sets off strong oscillations in $\mathrm{C} 1 / 2 / 4$ at a period of approximately $25 \mathrm{sec}$. C3 is outside of the half thickness of the current sheet and does not show any oscillations, see Fig. 13b; the gray dashed line shows the relative location of C3 with respect to the half thickness $\lambda$ of the current sheet. First, at 09:54 UT, when the current sheet has moved across Cluster, sending $\mathrm{C} 4$ to $\left|z_{0}\right|>\lambda$ and $\mathrm{C} 3$ to $\left|z_{0}\right|<\lambda$ do we see that the oscillations are highly suppressed in $\mathrm{C} 4$ and show up in $\mathrm{C} 3$, see Fig. 13e. This would indicate that the location of the spacecraft with respect to the neutral sheet is an important aspect for measuring these waves, in addition to the strong flow.
A similar event, in which the current sheet thins while Cluster is near the neutral sheet occurs on 12 August. Nakamura et al. (2002b) have made an extensive study of the current sheet thinning and show that before the flow burst, the current sheet is thick $\lambda>3000 \mathrm{~km}$. Only after 18:42 UT, when $\mathrm{C} 1$ and $\mathrm{C} 4$ see the flow burst (see Fig. 7), does the current sheet half thickness decrease to $\lambda \leq 500 \mathrm{~km}$, sending the spacecraft to either side of the neutral sheet. Before the flow burst and the current sheet thinning, interval $\mathrm{A}$, we see that there is very little spectral power density in the $30-60 \mathrm{mHz}$ frequency range. In interval $\mathrm{B} C 1 / 3 / 4$ show a peak in the spectrum around $40 \mathrm{mHz}$, whereas $\mathrm{C} 2$ just shows a drop off in spectral power density with increasing frequency. Clearly this event shows the importance of flow bursts for the occurrence of these waves, where no flows means no wave power.

What does this event explain about the location effect? The fits by Nakamura et al. show that most of the time the spacecraft are at $z_{o} \approx 0.1 R_{E} \approx 600 \mathrm{~km}$. This would mean that the spacecraft would be outside of 1 half thickness $\lambda$ and thus, one would expect suppressed or no wave power. This indeed seems to be the case for $\mathrm{C} 2$, which is the northernmost of the four spacecraft and furthest away from the neutral sheet. C2 shows no indication of wave power in the 30 $60 \mathrm{mHz}$ frequency range. The other spacecraft do show a spectral peak, however, compared with the first two events, the spectral power density is one order of magnitude smaller.

On 29 August the spacecraft remain in the Southern Hemisphere of the current sheet, only approaching the neutral sheet. There is a strong flow and a dipolariziation (see Fig. 8). The spectra show no significant peak in the 30 $60 \mathrm{mHz}$ frequency range. A fit of $B_{\mathrm{x}}$ to a Harris current sheet shows that during the chosen interval the half thickness is $\lambda \approx 1.5 R_{E}$, whereas the spacecraft are at $z_{0} \approx-0.5 R_{E}$. Although the flows are similar, as in the 17 July event, the spacecraft are not clustered around the neutral sheet, and that seems to have a significant influence on the wave power.

During the last event on 24 September, the spacecraft are clustered again around the neutral sheet, but there are no significant flows. The spectra show that there is very little spectral power density; the levels are two orders of magnitude 

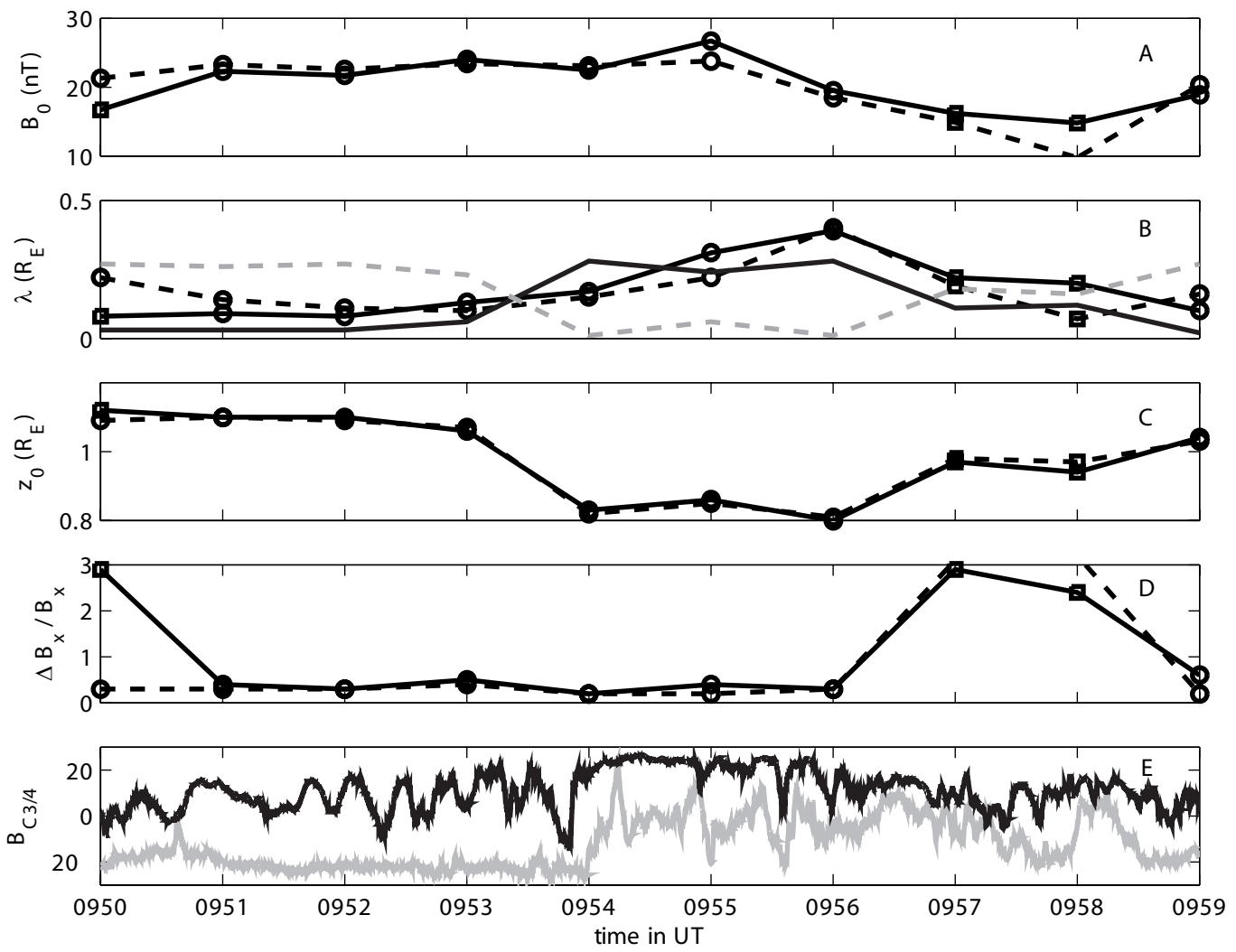

Fig. 13. Fitting $B_{\mathrm{X}}$ to the Harris current sheet model. For the thick solid line C2/3/4 are used to fit the three parameters in Eq. (1), C1 is used to check the fit. For the thick dashed line $\mathrm{C} 1 / 3 / 4$ are used to fit the three parameters and $\mathrm{C} 2$ is used to check the fit. Panel (a) shows $B_{0}$, the lobe field strength. Panel (b) shows the current sheet half thickness $\lambda$ in marked lines (circles and squares) and in unmarked lines the relative distance $\left(z_{\text {rel }}=z_{\mathrm{GSM}}-z_{0}\right)$ of C4 (solid black) and C3 (dashed gray) with respect to the neutral sheet. Panel (c) shows $z_{0}$, the offset of the neutral sheet with respect to the $z=0$ plane of the GSM coordinate system. Panel (d) shows a goodness-of-fit determined by the relative difference of the observed and the fitted $\Delta B_{\mathrm{X}} / B_{\mathrm{X}}=\left|\left(B_{\mathrm{X}, \mathrm{C} 1 / 2}-B_{\mathrm{X}, \text { fit }}\right) / B_{\mathrm{X}, \mathrm{C} 1,2}\right|$ for $\mathrm{C} 1$ (solid) and C2 (dashed). The symbols in the plots are indicative of the accuracy of the fit, for good fits a circle is used, for poor fits (i.e. $\Delta B_{\mathrm{X}} / B_{\mathrm{X}}>1$ ) a square is used. Panel (e) shows the MAG data for C3 (gray) and C4 (black). In the region where $z_{\mathrm{C} 4}<\lambda$ the 25 -sec waves are visible. They disappear when $z_{\mathrm{C} 4}>\lambda$ and appear erratically in the $\mathrm{C} 3$ data as $z_{\mathrm{C} 3}<\lambda$

smaller than for the 17 July event. Clearly being in the neutral sheet is of secondary importance to the wave power. A driver and the bursty flow need to be present.

\subsection{Origin of the $30-60 \mathrm{mHz}$ waves}

Roberts (1981 a, b) discussed the wave propagation in a magnetically structured (solar) atmosphere. In his simple model there is a uniform magnetic field in $|x|<x_{0}$, and outside there is no magnetic field. This model was modified by Smith et al. (1997), where the magnetic field structure was taken as that of a simple Harris current sheet. For a compressible plasma, with a Harris sheet type of magnetic field, Lee et al. (1988) solved the MHD equations to find the streaming sausage and kink instabilities.

The magnetic field strength $B_{\mathrm{t}}$ measured by FGM and the total plasma pressure $P_{\mathrm{p}, \mathrm{t}}$, measured by CIS-CODIF, are out of phase in their $\sim 25$-s oscillations. The magnetic pressure variations, $\Delta B^{2} / 2 \mu_{0}$, are almost balancing the plasma pressure variations, typically $<0.1 \mathrm{nPa}$, completely. This means that the observed waves in our events are sausage mode oscillations.

\subsection{Wave-flow relation}

We can determine the wave propagation direction and velocity if the spectral peaks for the different spacecraft line up sufficiently. We have found several cases in which this was possible. The wave velocities, $\mathbf{v}$, were determined in the spacecraft frame of reference, and they propagate in the same direction as the plasma flow, with propagation direction reversal if the plasma flow reverses direction, as in the 22 August event. In Table 1 we show $v_{\mathrm{x}}$, as determined in the above sections, and compare these values with the average flow $\bar{v}_{\mathrm{x}}$ and the maximum flow velocity $v_{\max }$ during the interval.

One must recognize that the waves are embedded in the flow, and thus, we have to determine the wave velocity $v_{\mathrm{pr}}$ in the plasma rest frame. The waves all have a velocity in the spacecraft reference frame that is in the same direction as the plasma flow, but slower. This means that in the plasma 
Table 1. Wave velocities $v_{\mathrm{x}}$ (rounded) determined from the magnetometer data, and the average and peak plasma flow velocities from the CODIF CIS data, and the wave velocity in the plasma rest frame $v_{\text {pr. }} \Delta \phi$ is the angle between the plasma flow and the wave propagation direction measured in the spacecraft' rest frame. The discrepancy in $v_{\text {pr }}$ for 29 August is cause by significant flows in $y$ and $z$

\begin{tabular}{rrrrrr} 
day & $v_{\mathrm{x}}$ & $\bar{v}_{\mathrm{x}}$ & $v_{\max }$ & $v_{\mathrm{pr}}$ & $\Delta \phi$ \\
\hline $17 / 07$ & 280 & 400 & 500 & -120 & $32^{\circ}$ \\
$22 / 08$ & -140 & -300 & -900 & 160 & $30^{\circ}$ \\
& 220 & 500 & 800 & -280 & $35^{\circ}$ \\
$12 / 08$ & 140 & 700 & 1000 & -600 & $39^{\circ}$ \\
$29 / 08$ & 260 & 300 & 600 & -40 & $35^{\circ}$
\end{tabular}

rest frame, the waves are moving tailward when the plasma is moving earthward (in the spacecraft' rest frame) and vice versa.

This is interesting in so far as the waves then, in the plasma frame, always move toward a possible X-point, staying behind the plasma flow. It is thus reasonable to argue that these compressional waves are caused by the interaction of the flow burst itself with the neutral sheet plasma. This is clearly a drift mode that tries to slow down the super-Alfvénic flow, as in the calculation by Lee et al. (1988).

Comparison of the wave velocity and the average plasma flow velocity shows that in the spacecraft' rest frame, the waves propagate at velocities slower than the plasma velocity. In the numerical calculation by Lee et al. (1988), one finds that the phase velocity of the waves is less than the flow burst velocity in the current sheet (see their Table 2). For a flow burst at twice the lobe Alfvén speed, the phase speed is approximately 1.8 times the lobe Alfvén speed. The phase speed in the numerical calculations is smaller than the flow speed, indicating that in the plasma flow reference frame, the waves will propagate backward. In our determination of the phase speed of the waves in the spacecraft' rest frame, we find that it is slower compared to the average plasma flow velocity than in the numerical calculations. This, however, is not a significant discrepancy, because the calculations are done for an ideal plasma of constant density in the current sheet, and we do not have perfect correlation between the spacecraft while determining the propagation velocity vector.

\subsection{Spectral power law}

In the various figures with the spectral power density we have also indicated the steepness of the spectral power over a frequency range of 80 to $1000 \mathrm{mHz}$. The spectrum for each spacecraft was fitted to a power law: $P(f)=P_{0} e^{-\alpha f}$. We find that the steepness is basically: $2.3 \leq \alpha_{80-1000} \leq 2.9$, with a few values lying outside this range. This range of $\alpha$ is at slightly higher values than observed by Bauer et al. (1995a), who found that $2.0 \leq \alpha_{30-2000} \leq 2.5$. This can easily be explained by the fact that they used a frequency range of 30 to $2000 \mathrm{mHz}$. Looking closely at the power spectra one can see that in many of the traces there is a "knee" in the spectrum near $80 \mathrm{mHz}$. The spectral power density is much flatter over the range of 10 to $80 \mathrm{mHz}$; in general, one finds in the cases presented in this paper that $\alpha_{30-80} \approx \alpha_{80-1000}-1$, indicating that two different mechanisms in these frequency ranges cause the turbulence. In general, it is important to note that the presence of these power laws strongly indicates that the turbulence in the neutral sheet during such events readily evolves into a well developed (probably internal) state.

Apart from having 4 spacecraft, there is another significant difference in our data set and that of Bauer et al. (1995a, b). In the latter, 15-min long intervals of data were investigated with strongly varying flow speeds (see Bauer et al. (1995b) Figs. 1, 2 and 3). Our dynamic spectra have been calculated over shorter intervals, in which there is only a high-speed flow, such that $v \gg c_{\mathrm{ms}}$, quite larger than the magnetosonic speed. This, together with the fact that we investigate waves at low frequencies $\omega \ll \omega_{\text {ci }}, f \ll 1 \mathrm{~Hz}$, allows the spectra obtained in this paper in the frequency $\omega$-domain to be directly mapped into the $k$-domain of wave numbers. Hence the spectra are dominated by the actual $k$-spectra, according to the Doppler shifted frequency $\omega^{\prime}=\omega \pm k v$ with $\omega \ll k v$ (see, e.g. also Borovsky et al. (1997)).

We may thus conclude that the spectra directly reflect the $k$-spectrum of the turbulence, in which case the slope $\alpha$ can be understood as the slope of the turbulent spectrum. First, the existence of such a slope indicates that the low frequency turbulence in the neutral sheet is fully developed, even during such bursty flows, and is nearly stationary within the margins of observation. Second, however, the value of $2<\alpha<3$ indicates that the spectrum is steeper than Kolmogorov $(\alpha \approx 1.7)$, with the turbulence in the neutral sheet becoming close to two dimensional. This is probably due to the limited zextension of the neutral sheet, which imposes a restriction on the third dimension. However, for purely 2-D turbulence, one should have $\alpha=3$. If $\alpha<3$, this implies that other processes are at work as well, like intermittency and spatial filamentations; more cannot be distinguished in the spectra. One can, however, use the observed break in the spectrum at about $40 \mathrm{mHz}$ to estimate at what scale the turbulence changes character. Using $v \approx 500 \mathrm{~km} / \mathrm{s}$ as a mean flow speed, and $\omega / 2 \pi \approx 40 \mathrm{mHz}$ we find the scale to amount to roughly $l \approx 2 R_{E}$. Hence, one may conclude that the break in the spectrum is caused by the transition of the turbulence from the inner part of the relatively weak field and high- $\beta$ region to the more external region where $\beta$ decreases.

Acknowledgements. We would like to acknowledge the Cluster Science Data System (CSDS). Furthermore we would like to thank Dr. J. Olson at the UAF Geophysical Institute for making the GIMA magnetometer data available on the web. The AE index was obtained from the World Data Center for Geomagnetism website in Kyoto. The work by MV and KHG was financially supported by the German Bundesministerium für Bildung und Forschung and the Zentrum fur Luft- und Raumfahrt under contract 50 OC 0104 and 50 OC 0103, respectively.

Topical Editor T. Pulkkinen thanks a referee for his help in evaluating this paper. 


\section{References}

Angelopoulos, V., Baumjohann, W., Kennel, C. F., Coroniti, R. V., Kivelson, M. G., Pellat, R., Walker, R. J., Lühr, H., and Paschmann, G.: Bursty bulk flows in the inner central plasma sheet, J. Geophys. Res., 97, 4027-4039, 1992.

Angelopoulos, V., Kennel, C. F., Coroniti, F. V., Pellat, R., Kivelson, M. G., Walker, R. J., Russell, C. T., Baumjohann, W., Feldman, W. C., and Gosling, J. T.: Statistical characteristics of bursty bulk flow events, J. Geophys. Res., 99, 21 257-21 280, 1994.

Balogh, A., Carr, C. M., Acuña, M. H., Dunlop, M. W., Beek, T. J., Brown, P., Fornacon, K.-H., Georgescu, E., Glassmeier, K.H., Harris, J., Musmann, G., Oddy, T., and Schwingenschuh, K.: The Cluster magnetic field investigation: overview of in-flight performance and initial results, Ann. Geophys., 19, 1207-1217, 2001.

Bauer, T. M., Baumjohann, W., Treumann, R. A., Sckopke, N., and Lühr, H.: Low-frequency waves in the near-Earth plasma sheet, J. Geophys. Res., 100, 9605-9617, 1995a.

Bauer, T. M., Baumjohann, W., and Treumann, R. A.: Neutral sheet oscillations at substorm onset, J. Geophys. Res., 100, $23737-$ $23743,1995 b$.

Baumjohann, W., Paschmann, G., and Lühr, H.: Characteristics of high-speed ion flows in the plasma sheet, J. Geophys. Res., 95, 3801-3809, 1990.

Baumjohann, W., Schödel, R., and Nakamura, R.: Burst of fast magnetotai flux transport, Adv. Space Res., 30, 2241-2246, 2002.

Borovsky, J. E., Elphic, R. C., Funsten, H. O., and Thomsen, M. F.: The Earth's plasma sheet as a lobaratory for flow turbulence in high- $\beta$ MHD, J. Plasma Phys.. 57, 1-34, 1997.

Büchner, J. and Kuska, J.-P.: Sausage mode instability of thin current sheets as a cause of magnetospheric substorms, Ann. Geophysicae, 17, 604-612, 1999.

Chen, S.-H. and Kivelson, M. G.: On ultralow frequency waves in the lobes of the Earth's magnetotail, J. Geophys. Res., 96, 15711-15 723, 1991.

Fruit, G., Louarn, P., Tur, A., and Le Quéau, D.: On the propagation of magnetohydrodynamic perturbations in a Harristype current sheet: 1. Propagation on discrete modes and signal reconstruction, J. Geophys. Res., 107(A11), 1411, doi: 10.1029/2001JA009212, 2002a.

Fruit, G., Louarn, P., Tur, A., and Le Quéau, D.: On the propagation of magnetohydrodynamic perturbations in a Harristype current sheet: 2. Propagation on continuous modes and resonant absorption, J. Geophys. Res., 107(A11), 1412, doi: 10.1029/2001JA009215, 2002b.

Glassmeier, K.-H., Motschmann, U., Dunlop, M., Balogh, A., Acuña, M. H., Carr, C., Musmann, G., Fornacon, K.-H., Schweda, K., Vogt, J., Georgescu, E., and Buchert, S.: Cluster as a wave telescope - first results from the fluxgate magnetometer, Ann. Geophys., 19, 1439-1447, 2001.

Harris, E. G.: On a plasma sheet separating regions of oppositly directed magnetic field, Nuovo Cimento, 23, 115-121, 1962.

Hruška, A. andHrušková, J.: Transverse structure of the Earth's magnetotail and fluctuations of the tail magnetic field, J. Geophys. Res., 75, 2449-2457, 1970.

Khurana, K. K., Chen, S.-H., Hammond, C. M., and Kivelson, M. G.: Ultralow frequency waves in the magnetotail of the Earth and the outer planets, Adv. Space Res., 12, 57-63, 1992.

Lee, L. C., Wang, S., Wei, C. Q., and Tsurutani, B. T.: Streaming sausage, kink and tearing instabilities in a current sheet with ap- plications to the Earth's magnetotail, J. Geophys. Res., 93, 7354$7365,1988$.

Nagai, T. and Machida, S.: Magnetic reconnection in the near-Earth magnetotail, New perspectives on the earth's magnetotail, Geophys. Monogr. Ser., 105, edited by Nishida, A. Baker, D. N., and Cowley, W. H.HF, pp. 211-224, AGU, Washington, DC, USA, 1998.

Nakamura, R., Baumjohann, W., Klecker, B., Bogdanova, Y., Balogh, A., Rème, H., Bosqued, J. M., Dandouras, I., Sauvaud, J. A., Glassmeier, K.-H., Kistler, L., Mouikis, C., Zhang, T. L., Eichelberger, H., and Runov, A.: Motion of the dipolarization front during a flow burst event ob-served by Cluster, Geophys. Res. Lett., 29, 1942, doi:10.1029/2002GL015763, 2002a.

Nakamura, R., Baumjohann, W., Runov, A., Volwerk, M., Zhang, T. L., Klecker, B., Bogdanova, Y., Roux, A., Balogh, A., Rème, H., Sauvaud, J. A., and Frey, H. U.: Fast flows during current sheet thinning, Geophys. Res. Lett., 29(29), 2140, doi:10.1029/2002GL016200, 2002b.

Raj, A., Phan, R., Lin, R. P., and Angelopoulos, V.: Wind survey of high-speed bulk flows and field-aligned beams in the near-Earth plasma sheet, J. Geophys. Res., 107(A12), 1419, doi:10.1029/2001JA007547, 2002.

Rème, H., et al.: First multi-spacecraft ion measurements in and near the Earth's magnetosphere with the identical Cluster ion spectrometry (CIS) experiment, Ann. Geophys., 19, 1303-1354, 2001.

Roberts, B.: Wave propagation in a magnetically structured atmosphere I: Surface waves at a magnetic interface, Solar Phys., 69, 27-38, 1981a.

Roberts, B.: Wave propagation in a magnetically structured atmosphere II: Waves in a magnetic slab, Solar Phys., 69, 39-56, $1981 b$.

Sergeev, V., Angelopoulos, V., Carlson, C., and Sutcliffe, P.: Current sheet measurements witin a flapping plasma sheet, J. Geophys. Res., 103, 9177-9187, 1998.

Sergeev, V., Runov, A., Baumjohann, W., Nakamura, R., Zhang, T. L., Volwerk, M., Balogh, A., Rème, H., Sauvaud, J. A., André, M., and Klecker, B.: Current sheet flapping motion and structure observed by Cluster, Geophys. Res. Lett., 30(6), 1327, doi:10.1029/2002GL016500, 2003.

Sigsbee, K., Cattell, C. A., Moser, F. S., Tsuruda, K., and Kokubun, S.: Geotail observations of low-frequency waves from 0.001 to $16 \mathrm{~Hz}$ during the November 24, 1996, geospace environment modeling substorm challenge event, J. Geophys. Res., 106, 435445, 2001.

Smith, J. M., Roberts, B., and Oliver, R.: Magnetoacoustic wave propagation in current sheets, Astron. Astrophys., 327, 377-387, 1997.

Tirry, W. J., Čadež, V. M., and Goossens, M.: MHD surface type quasi-modes of a current sheet model, Astron. Astrophys., 324, 1170-1178, 1997.

Volwerk, M., Glassmeier, K.-H., Runov, A., Baumjohann, W., Nakamura, R., Zhang, T. L., Klecker, B., Balogh, A., and Rème, H.: Kink mode oscillation of the current sheet, Geophys. Res. Lett., 30(6), 1320, doi:10.1029/2002GL016467, 2003.

Yoon, P. H. and Lui, A. T. Y.: On the drift-sausage mode in onedimensional current sheet, J. Geophys. Res., 106, 1939-1947, 2001.

Zhou, X.-Y., Russell, C. T., Gosling, J. T., and Mitchell, D. G.: Three spacecraft observations of the geomagnetic tail during moderately disturbed conditions: Structure and evolution of the current sheet, J. Geophys. Res., 102, 14 415-14 424, 1997. 